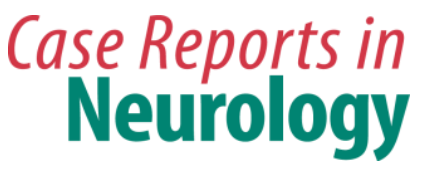

Case Rep Neurol 2016;8:193-198

DOI: $10.1159 / 000449281$

Publisned online: September 12, 2016
(C) 2016 The Author(s)

Published by S. Karger AG, Basel www.karger.com/crn

This article is licensed under the Creative Commons Attribution-NonCommercial 4.0 International License (CC BY-NC) (http://www.karger.com/Services/OpenAccessLicense). Usage and distribution for commercial purposes requires written permission.

\title{
Cerebral Cavernous Malformation: A Portuguese Family with a Novel CCM1 Mutation
}

\author{
João Pedro Marto ${ }^{a}$ Inês Gil ${ }^{b}$ Sofia Calado ${ }^{a, c}$ Miguel Viana-Baptista ${ }^{a, c}$ \\ a Department of Neurology, Hospital Egas Moniz, Centro Hospitalar Lisboa Ocidental, \\ Lisbon, Portugal; ${ }^{b}$ Department of Neuroradiology, Hospital Egas Moniz, Centro Hospitalar \\ Lisboa Ocidental, Lisbon, Portugal; ${ }^{\mathrm{C}}$ CEDOC (Chronic Diseases Research Center) - Nova \\ Medical School, Universidade Nova de Lisboa, Lisbon, Portugal
}

\section{Keywords}

Cerebral cavernous malformation · Cavernoma · CCM1 mutation · KRIT1

\begin{abstract}
Introduction: Cerebral cavernous malformation (CCM) is a vascular disorder characterized by the presence of central nervous system cavernomas. In familial forms, mutations in three genes (CCM1/KRIT1, CCM2/MGC4607 and CCM3/PDCD10) were identified. We describe a Portuguese family harboring a novel CCM1 mutation. Case Presentation: The proband is a woman who at the age of 55 years started to have complex partial seizures and episodic headache. Although nothing was found during her neurological examination, brain MRI showed bilateral, supra- and infratentorial cavernomas. She had a sister who, at the age 61 years, suffered a tonic-clonic seizure. Neurological examination was normal and imaging investigation demonstrated a right frontal intracerebral hemorrhage and multiple cavernomas. In the following years, she suffered several complex partial seizures and had a new intracerebral hemorrhage located in the right temporal lobe. Genetic analysis was performed and a novel nucleotide substitution, i.e. c.1927C>T (p.GIn643*) within the exon 17 of the CCM1 gene, was detected in both sisters. The substitution encodes a stop codon, with a consequent truncated KRIT1 protein, therefore supporting its pathogenic role. Further affected family members were detected, suggesting an autosomal dominant pattern of inheritance. Conclusion: We report a Portuguese family with a novel CCM1 (KRIT1) mutation - c.1927C>T (p.Gln643*). A better knowledge of the phenotype-genotype correlation is needed to improve the management of CCM patients.

(C) 2016 The Author(s) Published by S. Karger AG, Basel
\end{abstract}

KARGER

João Pedro Marto

Hospital Egas Moniz, Centro Hospitalar Lisboa Ocidental

Rua da Junqueira, $\mathrm{n}^{\circ} 126$

PT-1349-019 Lisbon (Portugal)

E-Mail joao.pedro.seabra.marto@gmail.com 


\section{Case Reports in Neurology}

\begin{tabular}{l|l}
\hline Case Rep Neurol 2016;8:193-198 \\
\hline DOI: 10.1159/000449281 & $\begin{array}{l}\text { C 2016 The Author(s). Published by S. Karger AG, Basel } \\
\text { www.karger.com/crn }\end{array}$ \\
\hline
\end{tabular}

Marto et al.: Cerebral Cavernous Malformation: A Portuguese Family with a Novel CCM1 Mutation

\section{Introduction}

Cerebral cavernous malformation (CCM) is a disorder defined by the presence of vascular malformations called cavernomas, histologically characterized by abnormally enlarged capillary cavities without intervening brain parenchyma [1]. CCM represents 5-13\% of all cerebral vascular malformations and its estimated prevalence is about $0.1-0.5 \%$ in the general population [1].

Both sporadic and familial forms have been identified. The former usually harbors a single lesion, whereas the latter is characterized by the presence of multiple lesions whose number is correlated with the patient's age. The proportion of familial cases is estimated to be between 10 and 50\% [2], with an autosomal dominant inheritance and an incomplete penetrance. The average age of onset is about 30 years, but symptoms can also start in early infancy or in old age. The clinical phenotype is highly variable, with seizures, cerebral hemorrhage, focal neurological deficits and headache being the main clinical presentations [3].

MRI T2*-weighted sequences usually show lesions with areas of mixed signal intensity, with a central reticular core and a peripheral rim of decreased signal intensity due to hemosiderin deposition [4]. Genetic linkage analysis mapped three CCM loci: CCM1 gene (KRIT1) at 7q, CCM2 gene (MGC4607) at 7p and CCM3 gene (PDCD10) at 3q [5, 6]. In familial cases, a causative mutation is found in $78 \%$ of patients, with CCM1 corresponding to more than $50 \%$ of mutations [5]. CCM1 encodes for the krev interaction trapped 1 (KRIT1) protein, which has a role in endothelial junctions and microtubule functions [6].

We describe a Portuguese family harboring a novel CCM1 mutation (fig. 1).

\section{Case Presentations}

\section{Patient 1}

The proband (II-6) is a 65-year-old woman. At the age of 55 years, complex partial seizures started and she also complained of episodic headache. General and neurological examinations were unremarkable. Brain MRI showed bilateral, supra- and infratentorial cavernomas, including the brain stem (fig. 2). EEG at that time displayed bilateral temporal paroxysmal activity, and the epileptic seizures were controlled with levetiracetam $500 \mathrm{mg}$ b.i.d. Genetic analysis of DNA extracted from peripheral blood lymphocytes was performed. CCM1/KRIT 1 coding exons and their intronic boundaries were PCR-amplified and screened with NM_194454.1 as the sequence reference. A novel nucleotide substitution c.1927C>T (p.Gln643*) within the exon 17 was found.

\section{Patient 2}

The proband's 67-year-old sister (II-4) experienced isolated tonic-clonic seizures at the age of 61 years. Neurological examination revealed a left superior quadrantanopia. Imaging investigation revealed a right frontal intracerebral hemorrhage and multiple bilateral supraand infratentorial cerebral cavernomas. One year thereafter, without evidence of rebleeding, the patient started to have partial complex seizures, controlled with levetiracetam $500 \mathrm{mg}$ b.i.d. After 4 years without symptoms, the patient suffered a new intracerebral hemorrhage in the right temporal lobe. A new brain MRI showed progression in the number and size of the cavernomas, a left V cranial nerve Schwannoma and a spinal cord cavernoma (fig. 3). Genetic analysis using the proband's mutation as reference displayed the same nucleotide substitution c.1927C>T (p.Gln643*) within CCM1 exon 17. 


\section{Case Reports in Neurology}

Marto et al.: Cerebral Cavernous Malformation: A Portuguese Family with a Novel CCM1 Mutation

Other Family Members

Other family members were not evaluated in our hospital, but as far as we know, the oldest sister (II-2) suffered an intracerebral hemorrhage at the age of 29 that was attributed to a cavernous malformation. In 1 of the proband's siblings (III-6) and in both siblings of patient II-4 (III-3 and III-5), without any history of neurological disease, i.e. epileptic fits or stroke, brain MRI was performed at the age of 31, 38 and 41 years, respectively, without evidence of any lesion. Although the proband's parents (I-4 and I-5) had no history of any CCM symptoms, one of her father's brothers (I-3) had a history of refractory seizures since his 4th decade of life. Also one of the proband's father nephews (III-10) was diagnosed with secondary epilepsy due to an isolated carvernoma at the age of 26.

\section{Discussion}

Familial CCM is a highly heterogeneous disorder with a wide range of phenotypical presentations. Three genes have been described in the familial cases (CCM1/KRIT1, CCM2/MGC4607, and CCM3/ PDCD10). Although more than 150 distinct mutations have been published, those mutations are highly stereotyped because almost all of them, through different mutation mechanisms, lead to premature termination codons. This stop codons result in truncated nonfunctioning proteins [5].

In the present case, the nucleotide substitution c.1927C > T (p.Gln643*) within the CCM1 loci exon 17 also encodes a stop codon, responsible for a truncated KRIT1 protein. This fact, associated with the concordance of the same mutation in 2 family members with multiple cavernous malformations, supports the pathogenic role of the identified mutation.

Of the patients with CCM who have multiple lesions and no family history, $75 \%$ of them have an asymptomatic parent with CCM lesion on brain MRI, due to incomplete clinical penetrance [7]. The clinical penetrance is estimated to be around $60 \%$. Spontaneous de novo mutations can also be responsible for sporadic cases with multiple CCM lesions [8].

As stated above, familial CCM is very heterogeneous, with a significant interfamilial and intrafamilial variability. Of the different clinical presentations, seizures are the most frequent [8], and they can be generalized, partial, or both types, as in our family. CCM lesions are highly epileptogenic due to blood breakdown products like iron surrounding the lesion and the subsequent local gliomatous reaction. Intracranial hemorrhage that occurred in patients II- 6 and II-4 is the second most common presentation. Individuals with CCMs experience new bleeding complications at an average rate of $0.7-1.1 \%$ per lesion per year [9] with an annual symptomatic hemorrhage rate that can reach $6.4 \%$ [10]. The risk of clinical manifestations increases with age, being previous gross hemorrhage, infratentorial lesions and female sex, factors associated with future clinical disability [9]. MRI T2-weighted gradient-echo sequences were considered to be the gold standard method to access the number and size of the lesions, as their signal evolution [11]. However, this imaging sequence cannot fully exclude the presence of the disorder, and the new susceptibility-weighted imaging sequences proved to be more sensitive to detect cavernomas [12].

As mentioned above, CCM familial cases usually present with multiple lesions, in both supra- and infratentorial localizations, as in the present case. Less frequently, spinal cord lesions have also been reported [13], as in patient II-4 (fig. 3). The association of CCM with extracerebral vascular malformations as well as with other tumors has been reported. As in the present family (patient II-4; fig. 3), CCM can be associated with schwannomas and other intracranial tumors [14]. All patients were managed in a conservative fashion. Surgical 
Marto et al.: Cerebral Cavernous Malformation: A Portuguese Family with a Novel CCM1 Mutation

treatment in CCM seems to be associated with worse outcomes over 5 years compared to conservative treatment [15].

\section{Conclusion}

We report a Portuguese family with a novel CCM1 (KRIT1) mutation. The disease phenotype and genotype characterization, as well as their correlation, are important to establish appropriate therapeutic approaches and clinical surveillance protocols, to define prognosis and to guide genetic counseling. Our findings add to the current understanding of CCM mutations and their associated phenotypes.

\section{Statement of Ethics}

Written informed consent was obtained from the proband (II-6) and patient II-4 for the publication of this case report and any accompanying images. A copy of the written consent is available for review by the Editor of this journal.

\section{Disclosure Statement}

There are no conflicts of interest.

\section{References}

1 Rigamonti D, Drayer BP, Johnson PC, Hadley MN, Zabramski J, Spetzler RF: The MRI appearance of cavernous malformations (angiomas). J Neurosurg 1987;67:518-524.

-2 Rigamonti D, Hadley MN, Drayer BP, Johnson PC, Hoenig-Rigamonti K, Knight JT: Cerebral cavernous malformations. Incidence and familial occurrence. N Engl J Med 1988;319:343-347.

-3 Labauge P, Denier C, Bergametti F, Tournier-Lasserve E: Genetics of cavernous angiomas. Lancet Neurol 2007;6:237-244.

-4 Brunereau L, Labauge P, Tournier-Lasserve E: Familiar form of intracranial cavernous angiomas: MR imaging findings in 51 families. Radiology 2000;214:209-216.

5 Denier C, Labauge P, Bergametti F, Marchelli F, Riant F, Arnoult M, et al: Genotype-phenotype correlations in cerebral cavernous malformations patients. Ann Neurol 2006;60:550-556.

-6 Sahoo T, Johnson EW, Thomas JW, Kuehl PM, Jones TL, Dokken CG, et al: Mutations in the gene encoding KRIT1, a Krev-1/rap1a binding protein, cause cerebral cavernous malformations (CCM1). Hum Mol Genet 1999;8:2325-2333.

7 Labauge P, Laberge S, Brunereau L, Levy C, Tournier-Lasserve E: Hereditary cerebral cavernous angiomas: clinical and genetic features in 57 French families. Société Française de Neurochirurgie. Lancet 1998;352:1892-1897.

8 Denier C, Labauge P, Brunereau L, Cavé-Riant F, Marchelli F, Arnoult M, et al: Clinical features of cerebral cavernous malformations patients with KRIT1 Mutations. Ann Neurol 2004;55:213-220.

-9 Gault J, Sain S, Hu LJ, Awad IA: Spectrum of genotype and clinical manifestations in cerebral cavernous malformations. Neurosurgery 2006;56:1278-1285.

10 Zabramski JM, Wascher TM, Spetzler RF, Johnson B, Golfinos J, Drayer BP, et al: The natural history of familial cavernous malformations: results of an ongoing study. J Neurosurg 1994;80:422-432.

11 Lehnhardt FG, von Smekal U, Ruckriem B, Stenzel W, Neveling M, Heiss WD, et al: Value of gradientecho magnetic resonance imaging in the diagnosis of familial cerebral cavernous malformation. Arch Neurol 2005;62:653-658. 


\section{Case Reports in Neurology}

Marto et al.: Cerebral Cavernous Malformation: A Portuguese Family with a Novel CCM1 Mutation

12 Souza JM, Domingues RC, Cruz LCH, Domingues FS, Iasbeck T, Gasparetto EL: Susceptibility-weighted imaging for the evaluation of patients with familial cerebral cavernous malformations: a comparison with T2-weighted fast spin-echo and gradient-echo sequences. Am J Neuroradiol 2008;29:154-158.

13 Labauge P, Bouly S, Parker F, Gallas S, Emery E, Loiseau H, et al: Outcome in 53 patients with spinal cord cavernomas. Surg Neurol 2008;70:176-181.

-14 Feiz-Erfan I, Zabramski JM, Herrmann LL, Coons SW: Cavernous malformation within a schwannoma: review of the literature and hypothesis of a common genetic etiology. Acta Neurochir 2006;148:647652.

15 Moultrie F, Horne MA, Josephson CB, et al: Outcome after surgical or conservative management of cerebral. Neurology 2014;83:582-589.
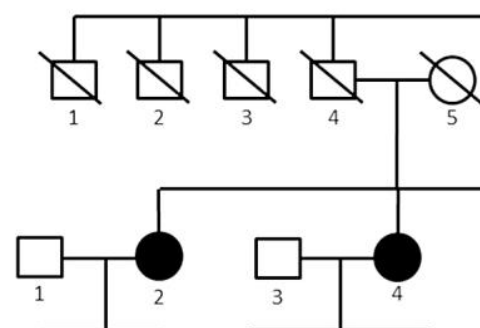

III

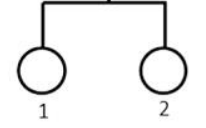

IV


Fig. 1. Portuguese family with a novel CCM1 mutation. The arrow indicates the index patient (II 6). All confirmed affected members are indicated by filled symbols. The line across a symbol means that the individual has died. 


\section{Case Reports in Neurology}

\begin{tabular}{l|l}
\hline Case Rep Neurol 2016:8:193-198 \\
\hline DOI: 10.1159/000449281 & $\begin{array}{l}\text { C 2016 The Author(s). Published by S. Karger AG, Basel } \\
\text { www.karger.com/crn }\end{array}$ \\
\hline
\end{tabular}

Marto et al.: Cerebral Cavernous Malformation: A Portuguese Family with a Novel CCM1 Mutation

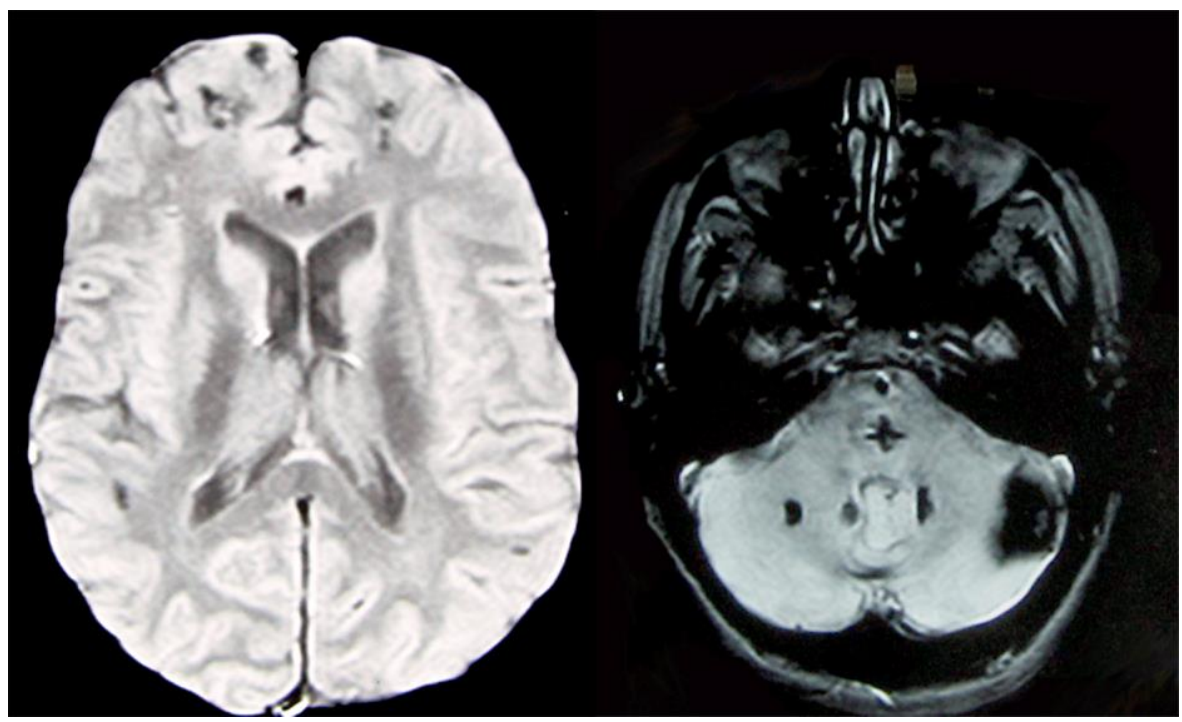

Fig. 2. Axial MRI T2-weighted gradient-echo sequence images show supratentorial and infratentorial cavernomas.

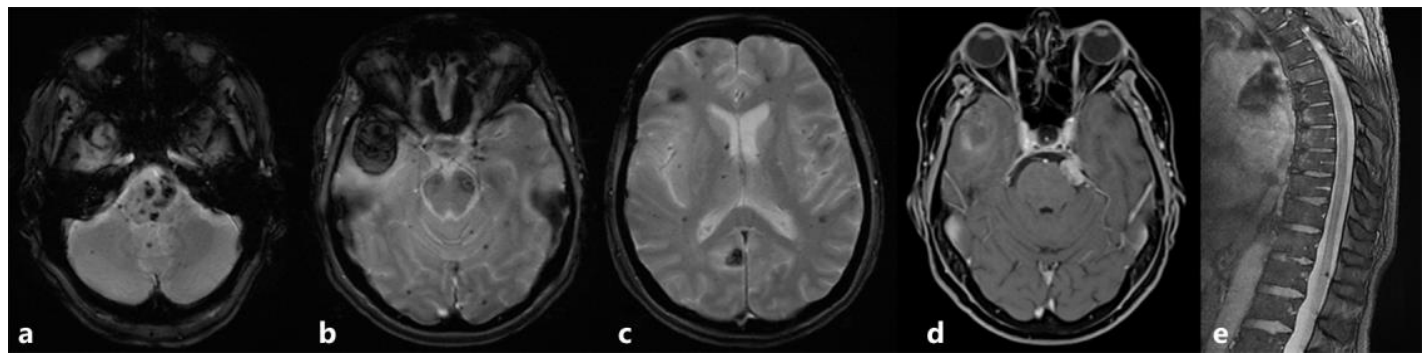

Fig. 3. a-c Axial MRI T2-weighted gradient-echo sequence images show supratentorial and infratentorial cavernomas. $\mathbf{d}$ Axial MRI T2-weighted gradient-echo sequence image shows a left V cranial nerve schwannoma. e Sagittal MRI T2-weighted gradient-echo sequence image shows a spinal cord cavernoma. 